\title{
Anesthesia Management of Bullous Emphysema in Patient Candidate for Craniotomy
}

\author{
Kamran Mottaghi, ${ }^{1}$ Saman Asadi, ${ }^{2}$ Farhad Safari, ${ }^{1}$ and Masoud Nashibi ${ }^{1,}$ \\ ${ }^{1}$ Department of Anesthesiology, Shahid Beheshti University of Medical Sciences, Tehran, Iran \\ ${ }^{2}$ Department of Anesthesiology, Shiraz University of Medical Sciences, Shiraz, Iran \\ "Corresponding author: Masoud Nashibi, Makhsous St, Kamali St, South Kargar Ave, Tehran, Iran. Tel: +98-2155424040, E-mail: masoudnashibi@sbmu.ac.ir
}

Received 2016 October 30; Accepted 2016 December 20.

\begin{abstract}
Introduction: Many patients with emphysema will develop cystic air spaces in the lung parenchyma known as bullae. Positive pressure ventilation increases the pressure in a bulla and increases the risk of rupture and tension pneumothorax. Therefore, anesthesia management, for surgeries other than lung volume reduction surgery (LVRS), is challenging in these patients.

Case Presentation: A 62-year-old male patient was brought to the emergency department due to a fall resulting in head trauma and a leak of CSF from a previous surgical site of a CP (cerebellopontine) angle tumor. The chest CT scan depicted bilateral bullae in the lungs. Anesthesia was induced and maintained with an inhalational method using Sevoflurane and spontaneous mask ventilation. Conclusions: Patients with bilateral bullae could be managed with spontaneous ventilation; one of the safe choices is inhalational induction and maintenance with Sevoflurane.
\end{abstract}

Keywords: Anesthesia, Bullous Emphysema, Craniotomy, Spontaneous Ventilation

\section{Introduction}

Many patients with emphysema will develop cystic air spaces in the lung parenchyma known as bullae. Bulla formation is due to loss of structural support tissue in the lung causing elastic recoil of surrounding parenchyma ( 1 , 2). Whenever positive pressure ventilation is used, the pressure in bullae will become positive in relation to the adjacent lung tissue and the bullae will expand with an increased risk of rupture and tension pneumothorax (1-3).

Although many studies have been performed regarding the medical or surgical management and anesthetic considerations in the surgical treatment of bullae, known as lung volume reduction surgery (LVRS), there are, however, limited reports about anesthesia management in surgeries other than LVRS in patients with bullous emphysema $(2,4)$.

Here we present a case of a patient with bilateral bullae, who was a candidate for craniotomy, which led to the challenge of providing him with induction as well as maintenance anesthesia.

\section{Case Presentation}

A 62-year-old male patient was brought to the emergency department with loss of consciousness due to experiencing a fall leading to head trauma, but without any convulsions. The patient had a history of a cerebellopontine (CP) angle tumor resection surgery 12 months prior.
Vital signs included a blood pressure of 120/95 $\mathrm{mmHg}$, a pulse rate of 90 beat/min, a room air $\mathrm{SpO}_{2}$ of $94 \%$ and a respiratory rate of $16 \mathrm{~b} / \mathrm{min}$.

Echocardiography variables were: normal left ventricle (LV) size, good LV systolic and diastolic function, LV ejection fraction of 55\%, no regional wall motion abnormality at rest, mild tricuspid regurgitation, mild aortic insufficiency, mild mitral regurgitation and a pulmonary artery pressure (PAP) of $26 \mathrm{mmHg}$. All other lab data were normal.

On the third day after intensive care unit (ICU) admission, the patient developed a cerebrospinal fluid (CSF) leak and therefore became a candidate for surgical repair. The leak emerged from his previous surgical site. Both a clinical examination and a computerized tomography(CT) scan did not show any signs of a raised intracranial pressure (ICP).

During the preoperative visit, a chest X-ray (CXR) displayed large emphysematous bullae. A chest CT scan also depicted bilateral bullae in the apical area of the lungs (Figures 1-3). The patient did not have a lung infection during the preoperative visit.

\subsection{Anesthesia}

The surgery was planned to be performed in supine position. All the standard monitoring was attached including electrocardiography, non-invasive blood pressure monitoring, end-tidal $\mathrm{CO}_{2}$, pulse oximetry, and cerebral state monitoring (CSM) for determining the depth of anesthesia. 


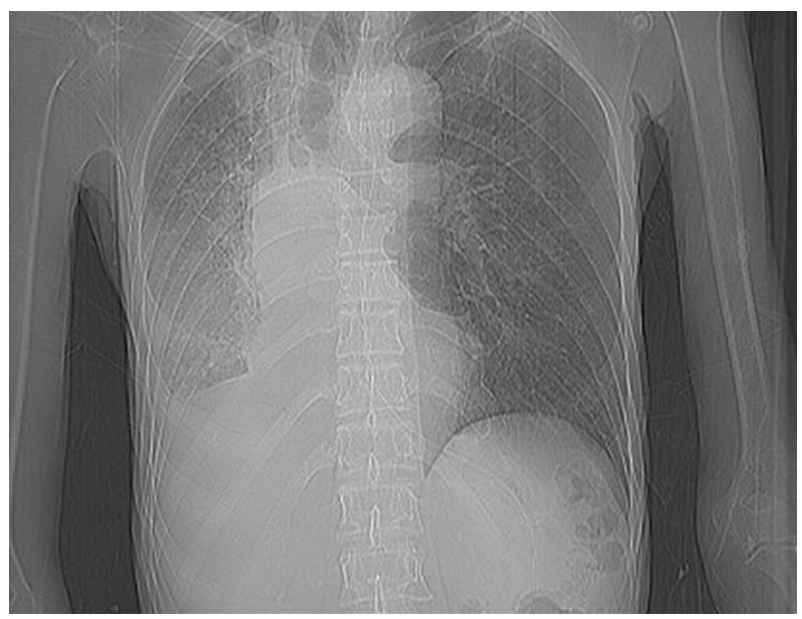

Figure 1. Chest X-Ray

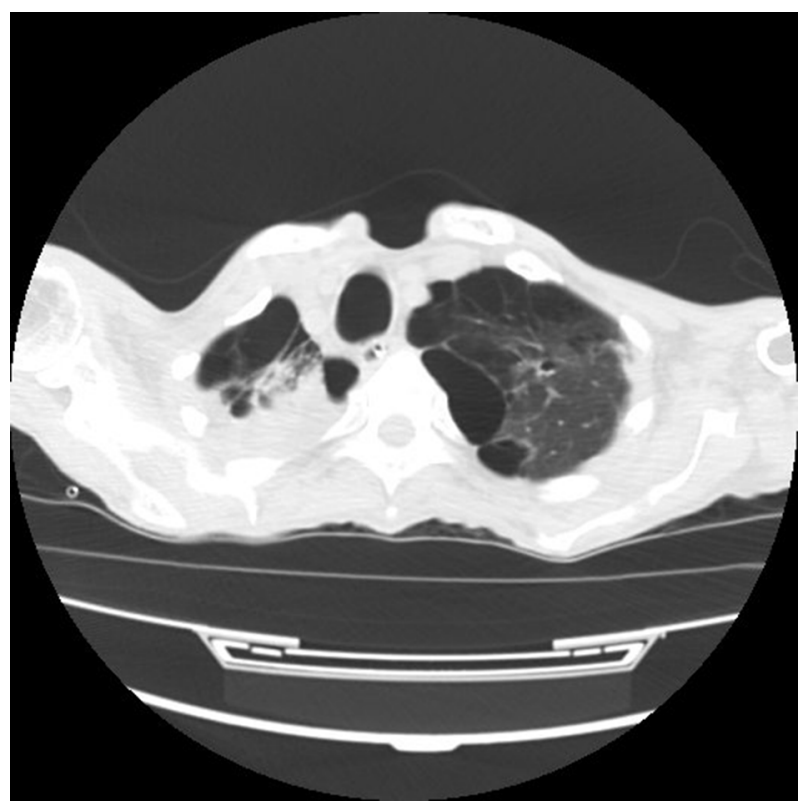

Figure 2. Chest CT Scan

The challenge for the anesthesia team was induction and maintenance of general anesthesia, and maintaining the airway, while avoiding positive pressure ventilation (PPV) to prevent bullae rupture.

Anesthesia was induced by inhalational method using Sevoflurane via spontaneous mask ventilation. By increasing Sevoflurane and the spontaneous mask ventilation, the depth of anesthesia was gradually increased to an appropriate level. At this point, the patient had a regular spontaneous breathing, fixed pupils at the midline and a CSM of

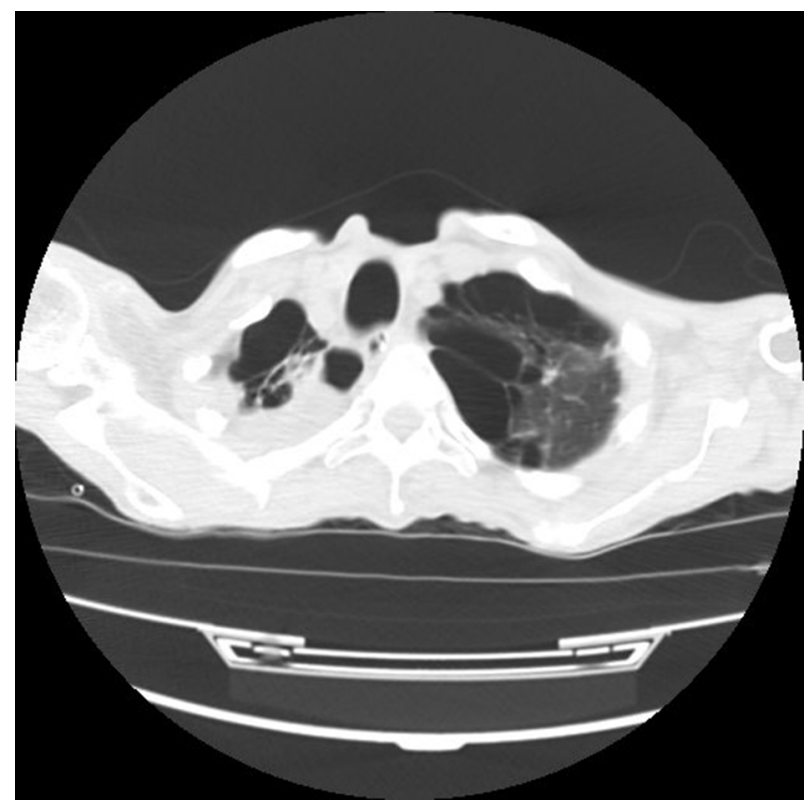

Figure 3. Chest CT Scan

35. Afterwards, Lidocaine $1 \mathrm{mg} / \mathrm{kg} / \mathrm{IV}$ was administered and the trachea intubated under direct laryngoscopy using an $8 \mathrm{~mm}$ ID spiral endotracheal tube. The patient had no movement or bucking during intubation. Anesthesia was maintained with Sevoflurane in order to keep the depth of anesthesia at a cerebral state index (CSI) of 40 - 50 with spontaneous ventilation. We asked the surgeon to use $5 \mathrm{ml}$ of Bupivicaine to provide local anesthesia at the incision line. Duration of surgery was 45 minutes and the patient had no movement or bucking during the entire procedure. No muscle relaxant was required. End tidal $\mathrm{CO}_{2}$ monitoring $\left(\mathrm{EtCO}_{2}\right)$ revealed that the patient did not have hypercapnia.

After craniotomy, the site of the CSF leak was covered with a dural patch and the surgical procedure was terminated after the dura and the cranium had been closed. At the end of surgery, Sevoflurane was discontinued and the trachea extubated. The patient was transferred to the ICU and a control CXR was performed. The patient did not develop any pneumothorax during the postoperative period.

\section{Discussion}

Different etiologies have been suggested as the probable origin of bullae such as smoking, cocaine abuse, sarcoidosis, Marfan's syndrome, Ehlers-Danlos syndrome, cadmium exposure (5), Marijuana abuse (6), and apnea diving activity during young adult ages (7). 
Bullae are thin-walled air-filled intraparenchymal lung spaces induced by the loss of alveolar structural tissue. Giant bullous emphysema (GBE) refers to bullae greater than $1 \mathrm{~cm}$ in diameter. Bullae do not take part in gas exchange and cause hypoxia and dyspnea (8). In the usual spontaneous ventilation in tidal volume range, bullae are more compliant than normal lung and preferentially fill during spontaneous ventilation. However, beyond the normal tidal volume range, bullae become much less compliant and the intra-bulla pressure rises acutely as airway pressure increases (9).

During spontaneous ventilation, the intra-bulla pressure is negative with respect to surrounding lung tissue (10). However, whenever positive pressure is used, the intra-bulla pressure will rise in relation to surrounding lung regions. There is a risk of hyperinflation and rupture whenever positive pressure is used $(1-3,8)$. Bulla rupture could be life threatening due to hemodynamic collapse from a tension pneumothorax or inadequate ventilation due to a resultant bronchopleural fistula $(1-3,11)$.

Inhalational and intravenous anesthetic agents have been used for the induction and maintenance of anesthesia in emphysematous patients, who are candidates for lung volume reduction surgery (LVRS). To achieve the goal of early tracheal extubation, short-acting hypnotics should be used (1).

Most reviews and reports are related to anesthesia management and ventilation during LVRS. The anesthetic considerations for patients with bullae are to prevent rupture and pneumothorax. It is best not to place a prophylactic chest tube because this may enter the bulla and create a fistula (12). These patients could be ventilated using a pressure or volume controlled mode. For the ventilation of two lungs, a tidal volume less than $9 \mathrm{~mL} / \mathrm{kg}$ and for the ventilation of one lung, less than $5 \mathrm{ml} / \mathrm{kg}$ with a low respiratory rate and a inspiration to expiration ratio of 1:3 to $1: 5$ is advisable to keep the peak airway pressure under $15 \mathrm{cmH}_{2} \mathrm{O}(1$, 2 ). By applying these adjustments, awareness would not be uncommon, therefore brain function monitoring should be considered (1). Nitrous oxide should be avoided in patients with blebs or bullae $(1,3)$.

In our case, the duration of surgery was 45 minutes, which is suitable for short-term preservation of spontaneous ventilation. It is important to note that in surgeries with longer duration, maintenance of spontaneous ventilation and appropriate depth of anesthesia at the same time might be difficult. One good option is using Sevoflurane.

In conclusion, patients with bilateral bullae could be managed with spontaneous ventilation; one of the choices is inhalational induction and maintenance with Sevoflurane. Lung bullae could be complicated by sudden rupture and development of a tension pneumothorax. Issues related to lung bullae that could arise should be reviewed beforehand.

\section{Footnotes}

Financial Disclosure: No disclosures. Funding/Support: None.

\section{References}

1. Brister NW, Barnette RE, Kim V, Keresztury M. Anesthetic considerations in candidates for lung volume reduction surgery. Proc Am Thorac Soc. 2008;5(4):432-7. doi: 10.1513/pats.200709-149ET. [PubMed: 18453351]

2. Ruiz Carbonell JR, Soliveres Ripoll J, Solaz Roldan C, Lluch Oltra A. [Anesthetic management in a patient with bullous emphysema]. Rev Esp Anestesiol Reanim. 2008;55(4):253-4. [PubMed: 18543512].

3. Roberta L, Hines KEM. Stoelting's anesthesia and co-existing disease. 6 ed. Philadelphia: Elsevier/Saunders; 2012.

4. Mozanski M, Rustecki B, Kalicki B, Jung A. Thermal imaging evaluation of paravertebral block for mastectomy in high risk patient: case report. J Clin Monit Comput. 2015;29(2):297-9. doi: 10.1007/s10877-0149599-x. [PubMed: 25059839].

5. Henao-Martinez AF, Fernandez JF, Adams SG, Restrepo C. Lung bullae with air-fluid levels: what is the appropriate therapeutic approach?. Respir Care. 2012;57(4):642-5. doi: 10.4187/respcare.01372. [PubMed: 22005505].

6. Golwala H. Marijuana abuse and bullous emphysema. Lung India. 2012;29(1):56-8. doi: 10.4103/0970-2113.92365. [PubMed: 22345916].

7. Luttecke-Hecht C, Hirche TO. Bullous emphysema - Not always nicotine-related!: Unusual distribution of emphysema in a patient with a rare hobby. Respiratory medicine case reports. 2014;12:44-6.

8. Van Bael K, La Meir M, Vanoverbeke H. Video-assisted Thoracoscopic Resection of a Giant Bulla in Vanishing Lung Syndrome: case report and a short literature review. J Cardiothorac Surg. 2014;9:4. doi: 10.1186/1749-8090-9-4. [PubMed: 24387696].

9. Hau AT, Jones BA, Olutoye OA. Apical bullae and spontaneous pneumothorax. Anesthesiology. 2013;119(1):201. doi: 10.1097/ALN.ob013e31828ce62e. [PubMed: 23435384].

10. Chakravarthy M, Jawali V. Differential ventilation with spontaneous respiration for bilateral emphysema. Asian Cardiovasc Thorac Ann. 2007;15(3):35-7. [PubMed: 17540979].

11. Schipper PH, Meyers BF, Battafarano RJ, Guthrie TJ, Patterson GA, Cooper JD. Outcomes after resection of giant emphysematous bullae. Ann Thorac Surg. 2004;78(3):976-82. doi: 10.1016/j.athoracsur.2004.04.005. [PubMed: 15337031] discussion 976-82.

12. Bansal S, Surve RM, Venkatapura RJ. Anesthetic management of a paraparetic patient with multiple lung bullae. J Neurosurg Anesthesiol. 2014;26(1):85-6. doi: 10.1097/ANA.0b013e3182973366. [PubMed: 24256764]. 